\title{
Surgical Management of Mucocele by Using Diode Laser: Two Case Reports
}

\begin{abstract}
:
Mucoceles are benign, mucus-containing cystic lesions of the minor salivary glands. They are not true cysts since most of them lack an epithelial lining. These lesion occur most commonly in the lower lip. This case report presents two cases of mucocele on the lower and upper lips. This lesion was diagnosed based on history, clinical finding and histopathological examination. The excision of the lesion was planed using diode laser. After re-evaluation of both the patients healing was satisfactory.
\end{abstract}

Key Words: Mucocele; Diode Laser; Mucus Extravasation Cyst; Excision; Recurrence.

\section{Introduction}

Mucoceles are defined as mucus-filled cavities that can appear in the oral cavity, appendix, gallbladder, paranasal sinuses or lacrimal sac. It is the result of accumulation of mucous due to the alteration in the minor salivary gland which causes limited swelling. It is seventeenth most common salivary gland lesions seen in the oral cavity [1].

Mucocele are characterized by the accumulation of liquid or mucoid material, giving rise to a rounded, well-circumscribed, transparent and bluish-colored lesion of variable size. Soft in consistency and fluctuant in response to palpation. These are painless and tend to relapse. Mucoceles are usually asymptomatic, though in some patients they can cause discomfort by interfering with speech, chewing or swallowing. However, in most cases these lesions rupture spontaneously or traumatically a few hours after being formed, with the release of a characteristic viscous, mucoid fluid. This may give the mistaken impression of healing, since the lesion decreases in size or disappears. However, once the small perforation allowing release of the mucocele contents has healed, the secretions accumulate again, and the lesion relapses. On the other hand, in the case of repeated trauma, the lesion may become nodular and firm in response to palpation, with rupture in this situation being more difficult [2].

Surgical excision of the lesion has been the main treatment option. However, other options have been reported in the literature such as the creation of a pouch (marsupialisation), freezing (cryosurgery), micromarsupialisation and laser vaporization. There are also some reports suggesting the use of corticosteroid injections as an alternative to surgery [3].

\section{Case Presentation}

CASE 1: A 38 year old male patient reported to Department of Periodontology, Rungta College of Dental Sciences and Research, Bhilai with chief complaint of swelling in the lower lip since 1 month. History revealed that the lesion began as a small nodular growth in the left commissural region, and gradually continues to grow to the present size. The patient was in a good systemic health and his family history, medical history was non-contributory. The dental history revealed that he had a habit of ghutkha chewing 3-4 packets a day since 20 years. He also reported habit of lip biting during stress. On intraoral examination, a pink colored, solitary swelling measuring about 2 $x 2 \mathrm{~cm}$ in size was found. On palpation the swelling was soft, fluctuant and non-tender. On the basis of history and clinical presentation, a provisional diagnosis of mucocele was made and an excisional biopsy was planned with laser and the same was explained to the patient and his consent was taken.

Local anesthesia (2\% lignocaine HCL with 1:80,000 Adrenaline) was administered taking care not to directly infiltrate the lesion to avoid compromising the biopsy results. Then the lesion was marked with the heamatoxlin pencil (Fig 1). The lip was then everted with digital pressure to increase the lesion's prominence. Patient and staff used special eye glasses for 
protection and all the laser safety protocol was followed prior to and during the laser procedure. A $940 \mathrm{~nm}$ diode laser (Ezlase, Biolase, USA) was used to excise the lesion. A circular incision

\section{Figure 1. Pre-oprative photograph}

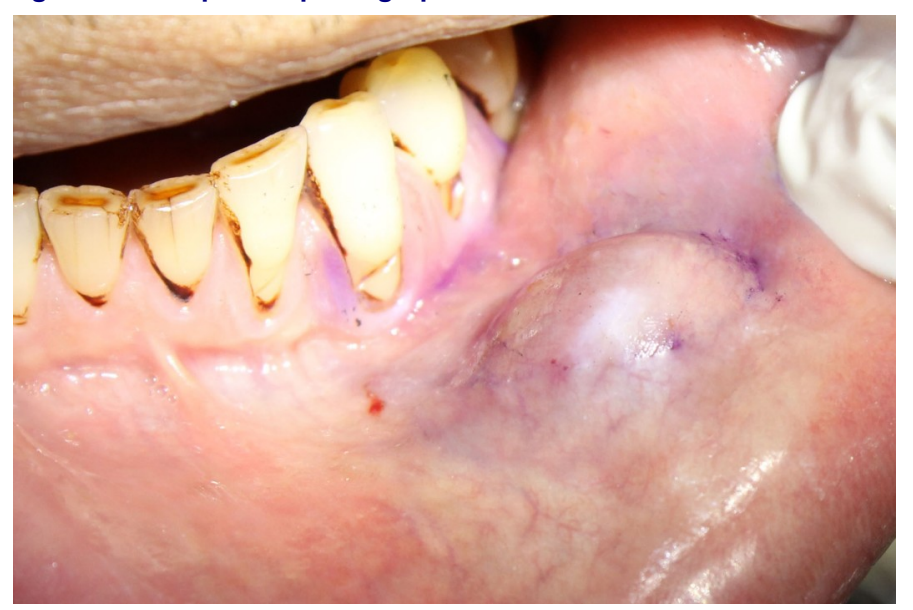

was made around the lesion with the capsule intact along with the thin border of healthy adjacent tissue. The enucleated area was further approximated and low level laser therapy was done (Fig 2). Then the exciseded tissue (Fig 3) was stored in formaline and further sent for histopathological examination.

\section{Figure 2. Excised mass.}

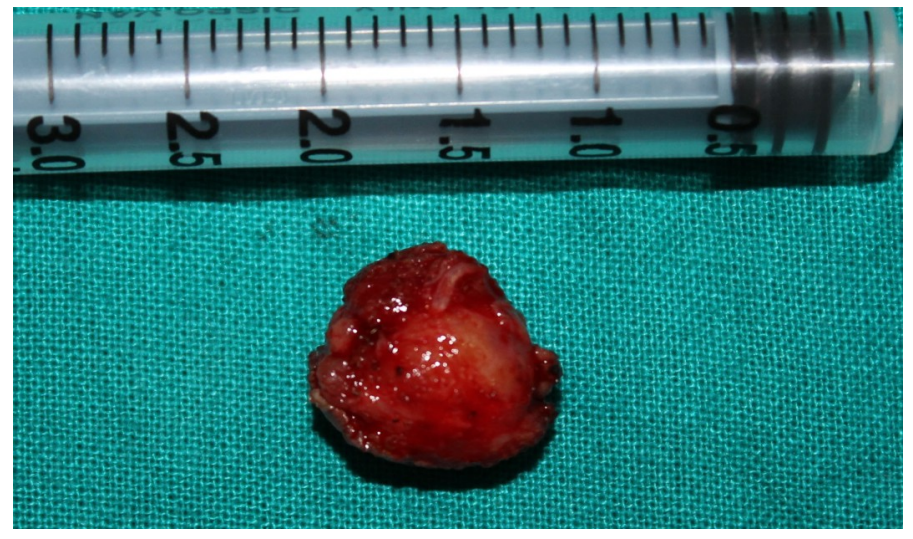

Figure 3. Post-operative .

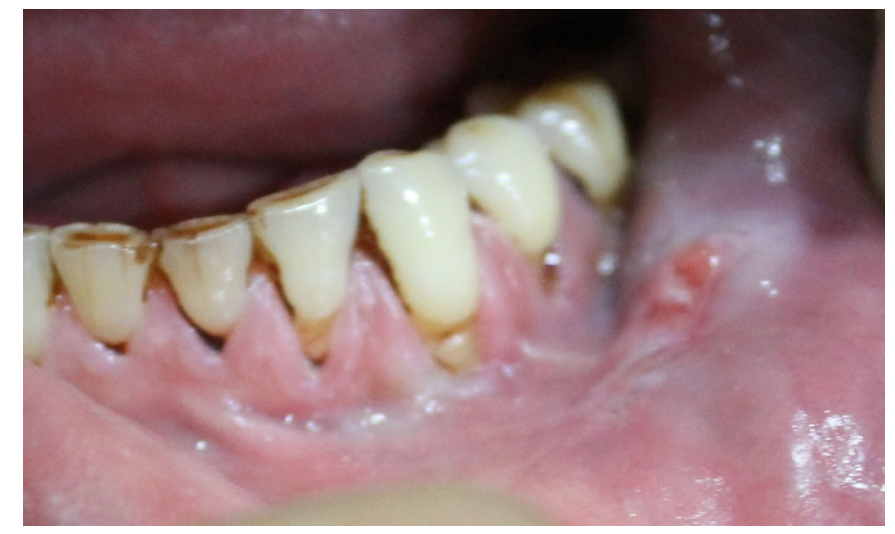

A postoperative instruction was given to the patient and was instructed to stop the habit of lip biting. The patient was recalled after 15 days for postoperative checkup (Fig 4). Patient is under observation and so far there is no evidence of recurrence.
Figure 4. Pre-operative.

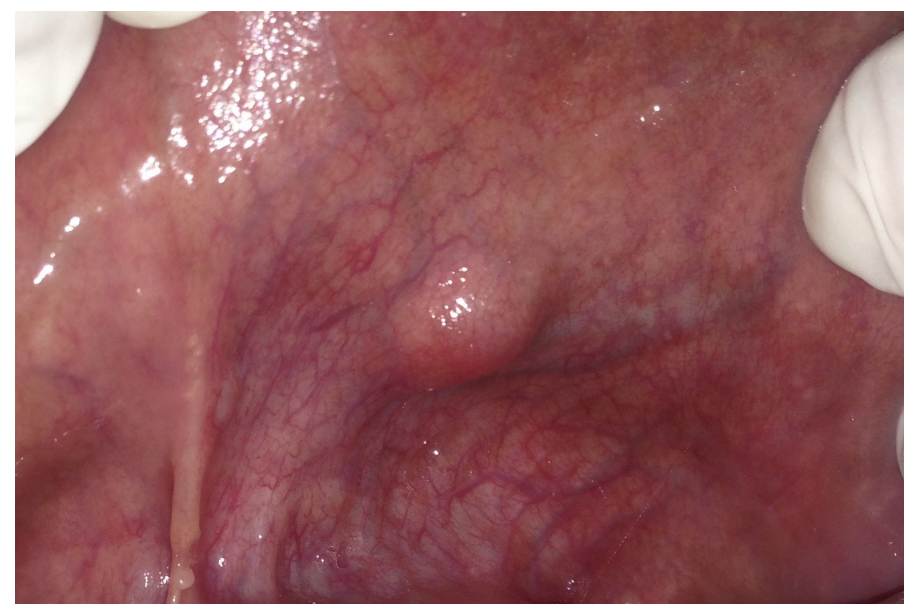

CASE 2: A 60 year old male patient visited to the Department with a chief complains of swelling in the upper lip since 15 days. History revealed that the lesion began as a small growth at the left commissural region which was gradually growing over the past 15 days. The patient reported that swelling was interfering with the speech and also that he was edentulous since 1 year and wanted the replacement of the same. On clinical examination, the swelling was pink measuring $1 \times 1 \mathrm{~cm}$ in size (Fig.5). On palpation the swelling was soft, fluctuant and non-tender. On the basis of history and clinical presentation, a provisional diagnosis of mucocele was made and an excisional biopsy was planned with lasers and the same was explained to the patient and his consent was taken. The procedure was performed same as case 1. The patient was recalled after 15 days for postoperative checkup.

Figure 5. Pre-operative .

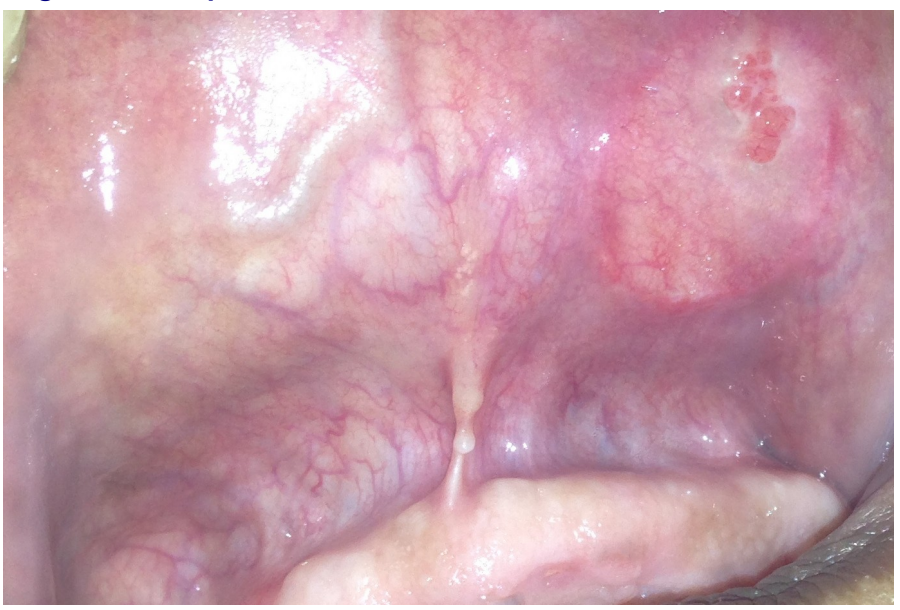

The histopathological report revealed normal minor salivary gland tissue and muscle fibres, thin epithelial lining is seen. A large portion of mucinophages with inflammatory cells and extravasted RBC's was seen.

Considering the history, clinical feature and histopathological report, a final diagnosis of 'Extravasated Mucocele' was made (6). 
Figure 6. Histopathological view

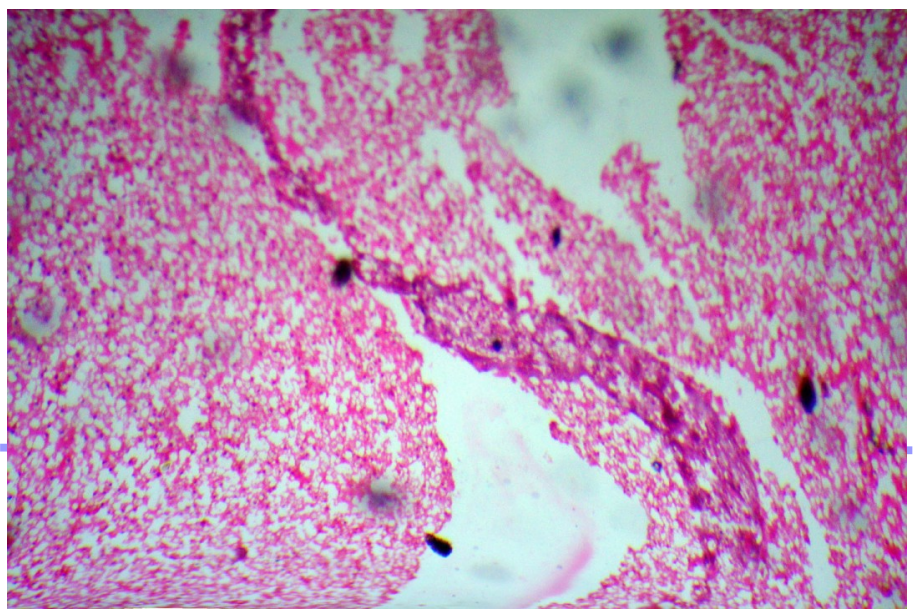

\section{Discussion}

The Mucocele is a salivary gland lesion of traumatic origin which is formed when the main duct of a minor salivary gland is torn with subsequent extravasation of the mucus into the fibrous connective tissue so that a cyst like cavity is produced and it is filled with mucin.

Salivary mucoceles are more common in the lower lip though they may develop in other areas such as the floor of the mouth, the cheek, the palate, retromolar fossa and the dorsal surface of the tongue. In our case report the mucoceles developed in the both upper and lower lip [4].

There are various different treatment options, including medication, Gamma-linolenic acid, cryosurgery, intralesional corticosteroid injection, micromarsupialization, marsupialization of the mucocele, conventional surgical removal of the lesion [6].

The surgical removal of the lesion sometimes leads to temporary paresthesia, fibrous scar formation \& recurrence of the lesion [8].

Vaporization with argon and Nd: YAG lasers has been described for the treatment of mucoceles [7]. Both laser procedures presented satisfactory results with low recurrence rates and were well-tolerated by the patients [8].

\section{Conclusion}

Lasers apply a great technology and are useful for soft tissue surgery in modern dentistry. In spite of all these advantages of using lasers in soft tissue incisions Dental lasers provide an easy and comfortable option of keeping the procedure efficacious as well as minimally invasive. In our cases, there was no bleeding during and after the procedure, No post operative swelling or any discomfort was noted. Uneventful healing after laser therapy adds to patient satisfaction.

\section{References}

1. Rao Prasana, Shetty S.R., Chatra L, Shenai P. Oral Mucocele - A Mini Review. Dentistry 2: 153. doi:10.4172/2161-1122.1000153.

2. Chawlaa Kriti, Lambab A.K. et al. Treatment of Lower Lip Mucocele with Er,Cr:YSGG Laser - A Case Report. J Oral Laser Applications 2010; 10: 181-185.

3. Alves A Levy, Nicoló Di Rebeca et al. Retention mucocele on the lower lip associated with inadequate use of pacifier. Dermatology Online Journal 2010; 16(7): 9.

4. A.K. Rashid, N. Anwar, A.M. Azizah, K.A. Narayan. Cases of mucocele treated in the Dental Department of Penang Hospital. Archives of Orofacial Sciences (2008); 3(1): 7-10.

5. Moraes Pde $\mathrm{C}$ et al. Liquid nitrogen cryosurgery for treatment of mucoceles in children. Pediatr Dent. 2012; 34 (2): 159-6.

6. Reinhard A. Neumann,Robert M. Knobler. Treatment of oral mucous cysts with an Argon Laser. Arch Dermatol. 1990; 126 (6):829-830.

7. Madan Nidhi, Rathnam Arun. Excision of Mucocele: A Surgical Case Report. Biological and Biomedical Reports 2012; 2(2): 115-18.

8. Pedron IG, Galletta VC, Azevedo LH, Correa L. Treatment of mucocele of the lower lip with diode laser in pediatric patients: presentation of 2 clinical cases. Pediatr dent. 2010; 32(7): 539-41. 